\title{
Clinical Characteristics of Patients with Dizziness According to the Level of Dizziness-related Disability
}

\author{
Emre Soylemez $^{1 \star}$, Suha Ertugrul ${ }^{2}$
}

${ }^{1}$ Department of Audiology, Karabuk University, Karabuk, TURKEY

${ }^{2}$ Department of Otorhinolaryngology, Karabuk University, Karabuk, TURKEY

*Corresponding Author: emresylmz28@gmail.com

Citation: Soylemez E, Ertugrul S. Clinical Characteristics of Patients with Dizziness According to the Level of Dizziness-related Disability. Electron J Gen Med. 2021;18(2):em275. https://doi.org/10.29333/ejgm/9693

\section{ARTICLE INFO}

Received: 18 Aug. 2020

Accepted: 1 Dec. 2020

\author{
ABSTRACT \\ Objective: This study aims to evaluate the clinical characteristics of patients with dizziness according to the level \\ of dizziness-related disability.
}

Methods: Vestibular system evaluation forms of the patients who applied to the otolaryngology outpatient clinic between June 2018 and January 2020 were reviewed retrospectively. Ninety patients with dizziness complaints were included in the study. These patients were divided into 3 groups as mild disability, middle disability and severe disability according to the Dizziness handicap inventory (DHI). Demographic characteristics, comorbidity, smoking and alcohol use, motion sickness, duration of dizziness, type of dizziness and vestibular test results (Fukuda test, tandem stance test, tandem walking test, positional tests, head impulse test (HIT), head shake test, caloric test, gaze test, oculomotor tests and spontaneous nystagmus test) were evaluated according to the level of dizziness-related disability.

Results: Twenty-one of the patients were male (21.3\%), 69 (78.7\%) were female and the mean age was $40.54 \pm$ 12.91; (range 15-73). Patients with cervical disc herniation, motion scikness, abnormal HIT, abnormal tandem stance test and prolonged dizziness had more severe dizziness-related disability level $(p<0.05)$. There was also a mild positive relationship between age and functional disability $(p<0.05)$.

Conclusion: Patients with motion sickness, cervical disc herniation, prolonged dizziness, abnormal tandem posture test and abnormal HIT have a more severe disability. These factors should be considered in dizziness therapies applied to decrease vestibular symptoms and improve quality of life.

Keywords: dizziness, vestibular, disability, motion sickness, cervical disc herniation

\section{INTRODUCTION}

Vestibular pathologies cause symptoms such as dizziness and imbalance in individuals and decrease the quality of life [1]. These individuals often have fear of falling due to dizziness, mobility limitation and psychological morbidity (anxiety and depression). Therefore, the goal of therapy options such as vestibular rehabilitation is to reduce the symptom of vestibular disease, remove dizziness-related disability and improve the quality of life [2]. Therefore, perception of vestibular symptoms and disability level in individuals have an important place in vestibular diseases.

The location and severity of the pathology can be determined with tests used to diagnose vestibular losses such as caloric test and VHIT. However, these tests do not give information about dizziness-related disability level (DDL) in dizzy patients. DDL is related to the perception of symptoms in individuals with vestibular disease. For this reason, psychometric evaluations such as scales and questionnaires are used to evaluate the perception of disability caused by dizziness. Dizziness handicap inventory (DHI) has been developed to evaluate physical, functional and emotional disability related to dizziness and vertigo caused by vestibular diseases [3]. DHI can be used to determine the level of disability, to prepare the treatment plan and to measure the outcome of the treatment in individuals with vestibular loss. There are some studies in the literature investigating the relationship between $\mathrm{DHI}$ and some vestibular tests and other scales [4-6]. However, dizziness disability perception is multifactorial and factors such as the psychological, demographic and social status of individuals can also affect the level of dizziness disability.

This study aims to evaluate the clinical characteristics of patients with dizziness according to level of dizziness-related disability.

\section{MATERIAL AND METHODS}

This study was designed retrospectively. Ethics committee approval was received for this study (2020/264). Patients who applied to the otolaryngology outpatient clinic between June 2018 and January 2020 with complaints of dizziness were evaluated. Patients who underwent vestibular testing after otorhinolaryngological examination were evaluated. The 
Table 1. Anamnesis section including demographic characteristics, social situations and comorbidities of the participants

\begin{tabular}{|c|c|c|c|c|}
\hline $1-$ & Age: & & & \\
\hline $2-$ & Gender: & & & \\
\hline $3-$ & Working status: & Student & Employe & Unemployed \\
\hline 4- & Do you smoke? & & Yes & No \\
\hline $5-$ & Do you use alcohol? & & Yes & No \\
\hline $6-$ & Do you have motion sickness? & & Yes & No \\
\hline 7- & Symptom of vestibular disease? & True vertigo & Lightheadedness & $\begin{array}{l}\text { Both of them (Lightheadedness } \\
\text { and True vertigo) }\end{array}$ \\
\hline $8-$ & Duration of symptoms (months) & & & \\
\hline 9- & $\begin{array}{l}\text { Have you fallen in the last three months due to your } \\
\text { vestibular disease? }\end{array}$ & & Yes & No \\
\hline $10-$ & Have you been diagnosed with migraine? & & Yes & No \\
\hline $11-$ & $\begin{array}{l}\text { Have you been diagnosed with a psychiatric illness such } \\
\text { as anxiety or depression? }\end{array}$ & & Yes & No \\
\hline $12-$ & Have you been diagnosed with diabetes? & & Yes & No \\
\hline $13-$ & Have you been diagnosed with hypertension? & & Yes & No \\
\hline 14- & $\begin{array}{c}\text { Have you been diagnosed with hyperthyroidism or } \\
\text { hypothyroidism? }\end{array}$ & & Yes & No \\
\hline $15-$ & Do you have a cervical disc herniation? & & Yes & No \\
\hline 16- & Do you have another illness? & & & \\
\hline
\end{tabular}

vestibular evaluation forms of the patients were scanned from the archive. Patients with an orthopedic disorder and mental deficiency according to data collection forms were not included in the study. As a result, ninety dizzy patients were included in the study.

The data collection form consists of three sections: anamnesis, vestibular tests and DHI. The anamnesis section contains questions about demographic features, social status and comorbidities (Table 1).

\section{Dizziness Handicap Inventory (DHI)}

DHI, which is used to determine the level of dizziness disability in vestibular diseases, was developed by Jacobson et al. [3]. It consists of 25 questions, 9 questions evaluating functional disability, 9 questions evaluating emotional disability and 7 questions evaluating physical disability. Each question can be given 3 different answers: No (0 score), Sometimes ( 2 scores) and Yes (4 scores), and the total score is evaluated over 100. It was reported that the total score of DHI has a high internal consistency ( $\alpha: 0.89$ ) and its subscales have good internal consistency ( $\alpha$ : 0.72-0.85) [3]. In our study, patients were divided into 3 groups as 0-30 mild disability, 3260 moderate disability and 62-100 severe disability according to the total score [7].

\section{Vestibular Tests}

\section{Dynamic and static balance tests}

Fukuda test and tandem walking test were used to evaluate the dynamic balance skills of the patients. For the Fukuda test, the patient was asked to stand, join his feet, bring his arms to 90 degrees of extension, and take 50 steps with eyes-closed. At the end of 50 steps, the amount of rotation between the start position and the end position of the individual was measured. Rotation angle of more than 45 degrees was accepted as abnormal Fukuda test. For the tandem walking test, the patient was asked to put one end of the foot in contact with the heel of the other foot (tandem position) while standing. The patient was then asked to walk 2 meters in a straight line. It was considered abnormal that the patient could not walk on the straight line, raise his arms to balance or take steps not to fall. The test was applied to each patient 3 times. In patients who could not complete in 2 of the 3 tests, the tandem walking test was considered abnormal.

Static balance skills of the patients were evaluated with the romberg test and tandem stance test. For the Romberg test, the patient was asked to stand, hang his arms to the sides and stand with eyes closed in this position. In the tandem stance test, the patient was asked to stand, put one end of the foot in contact with the heel of the other foot, and stand in this position with eyes closed. In these tests, patients were asked to maintain their balance for 30 seconds. The results of patients who could not maintain their balance for 30 seconds, lift their arms or take a step to balance, move their feet, were considered abnormal. Each test was applied to each patient 3 times. In patients who could not complete in 2 of the 3 tests, the test was considered abnormal.

\section{Dynamic positional tests}

Dynamic positional tests were performed on patients with Micromedical VNG device. Anterior and posterior semisurcular canals (SSCS) were evaluated by the Dix Hallpike maneuver. While the patient was sitting on the stretcher, his head was turned 45 degrees to the side, and the patient was quickly laid on his back, with the patient's head at 25-30 degrees of hyperextension. Lateral SSCs were evaluated with the supine roll maneuver. While the patient was lying on the stretcher with his head at 30 degrees of flexion, the patient's head was quickly turned 90 degrees to the side. Dynamic positional tests were considered positive in the presence of characteristic nystagmus specific to SSCS.

\section{Vestibulo-ocular tests}

Vestibulo-ocular reflexes (VOR) of the lateral SSC were evaluated with caloric test, head shake test and head impulse test (HIT). The caloric test was performed with the Aquastar air caloric stimulator device at temperatures of 47 degrees (warm air) and 27 degrees (cold air). When the patients were lying on their backs and their heads flexed at 30 degrees, goggles covers were closed and caloric stimulation was applied for 1 minute. The nystagmus formed were recorded for 2 minutes, and analyzed with VNG software. For unilateral canal parasis, nystagmus slow phase rates were considered as $<25 \%$. For bilateral canal parasis, the nystagmus maximum amplitude 
Table 2. Total DHI, physical disability, emotional disability and functional disability scores according to genders

\begin{tabular}{|c|c|c|c|}
\hline \multirow[b]{2}{*}{$\begin{array}{l}\text { Dizziness Handicap } \\
\text { Inventory }\end{array}$} & \multicolumn{2}{|c|}{ Genders } & \multirow[b]{2}{*}{$p^{*}$ value } \\
\hline & $\begin{array}{c}\text { Female } \\
\text { Mean } \pm \text { sd or median (min-max) }\end{array}$ & $\begin{array}{c}\text { Male } \\
\text { Mean } \pm \text { sd or median (min-max) }\end{array}$ & \\
\hline Total DHI score & $43.30 \pm 23.20$ & $26(2-90)$ & 0.316 \\
\hline Physical disability & $15.22 \pm 7.26$ & $12(0-26)$ & 0.366 \\
\hline Emotional disability & $8(0-34)$ & $6(0-32)$ & 0.370 \\
\hline Functional disability & $18(0-36)$ & $12(0-36)$ & 0.255 \\
\hline
\end{tabular}

DHI: dizziness handicap Inventory * Mann Whitney-U test

value resulting from warm and cold caloric stimulation of the same ear was accepted as $<12$ degrees / second.

The head shake test was used to evaluate the VOR asymmetry in the lateral SSCs. While the patient's head was at 30 degrees of flexion, the head shook left and right for 20 seconds. If nystagmus occurred at the end of the test, the test was considered abnormal.

For HIT, the patient's head was at 30 degrees of flexion. The patient was asked to fix his eyes to the clinician's nose, and the patient's head was turned unexpectedly 20 degrees to the right or left. If the eyes were not fixed during the test and a catch-up saccade occurred, the test was considered abnormal. The test was repeated 3 times for each side for control.

\section{Oculomotor tests, Gaze and Spontaneous nystagmus test}

Oculomotor tests, gaze and spontaneous nystagmus test were applied to the patients with Micromedical VNG. Saccade, smooth pursuit and optokinetic tests were applied to the patients to evaluate the oculomotor functions. To perform the oculomotor tests and gaze test, the patient was asked to follow the target on the light bar. In the spontaneous nystagmus test, the covers of the goggles were closed. The test was considered positive in the presence of nystagmus.

\section{Statistical Analysis}

Statistical analysis was performed with SPSS 21 (SPSS Inc., Chicago, IL, USA). Normality distribution was examined by the Shapiro-Wilk test. Mann Whitney-U test was used to compare gender and $\mathrm{DHI}$ groups. The chi-square test was used to investigate the correlation between categorical variables. $\mathrm{P}<0.05$ was accepted as statistically significant.

\section{RESULTS}

Sixty-nine $(78.7 \%)$ of the patients included in the study were female and $21(21.3 \%)$ were male, and the mean age of the patients was $40.54 \pm 12.91$ (15-73). There was no difference between genders in terms of Total (T)-DHI and DHI subgroups (functional, emotional and physical disability) (Table 2, p> 0.05).

The mean T-DHI score of the patients was $42.02 \pm 24.64$ (2$98)$. In the subscales, the mean physical disability score of the patients was $14.78 \pm 7.84$ (0-28), the mean emotional disability score was $10.40 \pm 9.09(0-34)$, and the mean functional score was $16.80 \pm 60.65(0-36)$. The mean duration of dizziness (months) was $17.58 \pm 29.63$ (0.5-148). There was no significant relationship between the ages of the patients and T-DHI, physical disability and emotional disability (P: 0.136; 0.719; 0.265 , respectively). However, there was a positive correlation between the ages and functional disability (P: $0.028 \mathrm{r}: 2.3)$. In addition, there was a positive correlation between duration of dizziness and T-DHI, functional, emotional and physical disabilities (P: 0.008 r: 2.7; 0.022 r: 2.4; 0.036 r: 2.2; 0.004 r: 3.0, respectively).

There was no relationship between T-DHI and working status, dizziness types, falling state, smoking, alcohol use, migraine, diabetes, anxiety or depression, thyroid disease, hypertension, sinusitis ( $p>0.05$ ). However, patients with cervical disc herniation and motion sickness were found to have more severe dizziness disability (Table 3, $p<0.05$ ).

There was no relationship between T-DHI and fukuda test, tandem walking test, romberg test, positional tests, caloric test, head shake test, gaze test, oculomotor tests and spontaneous nystagmus test ( $p>0.05)$. However, patients with abnormal tandem stance test and positive HIT test had more severe dizziness disability (Table 4, $p<0.05$ ).

\section{DISCUSSION}

In this study, clinical characteristics of patients with dizziness according to the level of dizziness-related disability were investigated. It has been found that patients with motion sickness, cervical disc herniation, abnormal tandem stance test, abnormal HIT and longer duration of dizziness have a more severe DDL. In addition, a positive correlation was found between the ages of patients and the level of functional disability.

The DDL is multidimensional. Therefore, the relationship between the DDL and other scales, diseases has been frequently investigated [5,9]. In our study, $54(60 \%)$ of the individuals did not have any comorbidity. However, 36 (40\%) of the individuals had some comorbidities. There was no difference in DDL in individuals with migraine, diabetes, hypertension, thyroid, sinusitis and anxiety and/or depression. However, in our study, individuals with motion sickness and cervical disc herniation had more severe DDL. Motion sickness is generally stimulated by vehicle movements or visual images that cause sensory conflict. These warnings reveal symptoms such as nausea, dizziness, headache and sweating in sensitive individuals, The most common view for the motion sickness etiology is mismatch or complexity of vestibular, visual, proprioceptive and kinesthetic inputs [8]. As can be seen in healthy individuals, vestibular diseases can increase or decrease motion sickness sensitivity. However, there are a limited number of studies in the literature investigating the relationship between motion sickness and DDL [9]. Henriques et al. [9] investigated the relationship between Motion Sickness Susceptibility Questionnaire (MSSQ-Short form) and balance tests and DDL in children. In their study, they stated that there is a relationship between MSSQ-Short form and DDL and balance tests. Similarly, individuals with motion sickness had more severe DDL in our study. Individuals with motion sickness, who are more sensitive to the inputs required to maintain balance, may also have more sensitive perception of 
Table 3. Working status of patients, symptoms of vestibular disease, falling states, smoking, alcohol use and comorbidities are shown according to $\mathrm{DHI}$ groups

\begin{tabular}{|c|c|c|c|c|c|c|c|}
\hline & \multicolumn{6}{|c|}{ Dizziness Handicap Inventory } & \multirow{3}{*}{$\mathbf{P}^{\star}$ value } \\
\hline & \multicolumn{2}{|c|}{$\begin{array}{c}\text { Mild disability } \\
\mathrm{n}: 33 \\
\end{array}$} & \multicolumn{2}{|c|}{$\begin{array}{c}\text { Moderate disability } \\
\mathrm{n}: 36 \\
\end{array}$} & \multicolumn{2}{|c|}{$\begin{array}{c}\text { Severe disability } \\
\mathrm{n}: \mathbf{2 1} \\
\end{array}$} & \\
\hline & $\mathbf{n}$ & $\%$ & $\mathbf{n}$ & $\%$ & $\mathbf{n}$ & $\%$ & \\
\hline Working status & & & & & & & 0.065 \\
\hline Unemployed & 2 & 6.0 & 1 & 3.0 & 0 & 0 & \\
\hline Employe & 11 & 33.3 & 4 & 12.1 & 9 & 42.8 & \\
\hline Retired & 3 & 9.0 & 1 & 3.0 & 1 & 4.7 & \\
\hline Housewife & 13 & 39.3 & 23 & 69.6 & 11 & 52.3 & \\
\hline Student & 4 & 12.1 & 7 & 21.2 & 0 & 0 & \\
\hline Symptoms of dizziness & & & & & & & 0.468 \\
\hline True vertigo & 17 & 51.5 & 17 & 51.5 & 7 & 33.3 & \\
\hline Lightheadedness & 11 & 33.3 & 9 & 25.0 & 9 & 42.8 & \\
\hline $\begin{array}{c}\text { Both of them (True vertigo and } \\
\text { lightheadedness) }\end{array}$ & 5 & 15.1 & 10 & 27.7 & 5 & 23.8 & \\
\hline Falling & 4 & 12.1 & 6 & 16.6 & 4 & 19.0 & 0.769 \\
\hline Smoking & 8 & 24.2 & 5 & 13.8 & 7 & 33.3 & 0.220 \\
\hline Alcohol use & 1 & 3.0 & 2 & 5.5 & 2 & 9.5 & 0.597 \\
\hline Motion sickness & 3 & 9.0 & 8 & 22.2 & 10 & 47.6 & 0.005 \\
\hline Migraine & 4 & 12.1 & 6 & 16.6 & 5 & 23.8 & 0.532 \\
\hline Anxiety and / or depression & 4 & 12.1 & 2 & 5.5 & 3 & 14.2 & 0.474 \\
\hline Diabetes & 1 & 3.0 & 3 & 8.3 & 3 & 14.2 & 0.318 \\
\hline Thyroid disease & 0 & 0 & 3 & 8.3 & 0 & 0 & 0.098 \\
\hline Hypertension & 0 & 0 & 4 & 11.1 & 3 & 14.2 & 0.101 \\
\hline Sinusitis & 1 & 3.0 & 0 & 0 & 2 & 9.5 & 0.153 \\
\hline Cervical Disc Herniation & 1 & 3.0 & 11 & 33.3 & 7 & 33.3 & 0.006 \\
\hline
\end{tabular}

${ }^{*}$ Chi-square test

Table 4. Abnormal vestibular test results according to $\mathrm{DHI}$ groups

\begin{tabular}{|c|c|c|c|c|c|c|c|}
\hline & \multicolumn{6}{|c|}{ Dizziness Handicap Inventory } & \multirow{3}{*}{$\mathbf{P}^{*}$ value } \\
\hline & \multicolumn{2}{|c|}{$\begin{array}{c}\text { Mild disability } \\
\mathrm{n}: 33\end{array}$} & \multicolumn{2}{|c|}{$\begin{array}{c}\text { Moderate disability } \\
\mathrm{n}: 36\end{array}$} & \multicolumn{2}{|c|}{$\begin{array}{c}\text { Severe disability } \\
\mathrm{n}: 21\end{array}$} & \\
\hline & $\mathbf{n}$ & $\%$ & $\mathbf{n}$ & $\%$ & $\mathbf{n}$ & $\%$ & \\
\hline Fukuda test & 13 & 39.3 & 15 & 41.6 & 12 & 57.1 & 0.402 \\
\hline Right rotation & 7 & 21.2 & 6 & 16.6 & 2 & 9.5 & \\
\hline Left rotation & 6 & 18.1 & 9 & 25.0 & 10 & 47.6 & \\
\hline Tandem walking test & 2 & 6.0 & 6 & 16.6 & 6 & 28.5 & 0.082 \\
\hline Tandem stance test & 12 & 36.3 & 22 & 61.1 & 15 & 71.4 & 0.024 \\
\hline Romberg test & 1 & 3.0 & 3 & 8.3 & 3 & 14.2 & 0.318 \\
\hline Dynamic positional tests & 4 & 12.1 & 2 & 5.5 & 4 & 19.0 & 0.287 \\
\hline Dix hallpike & 4 & 12.1 & 2 & 5.5 & 3 & 14.2 & \\
\hline Supine roll & 0 & 0 & 0 & 0 & 1 & 4.7 & \\
\hline Caloric test & 11 & 33.3 & 15 & 41.6 & 5 & 23.8 & 0.386 \\
\hline Right canal parasis & 6 & 16.1 & 6 & 16.6 & 4 & 19.0 & \\
\hline Left canal parasis & 4 & 12.1 & 5 & 13.8 & 0 & 0 & \\
\hline Bilateral canal parasis & 1 & 3.0 & 4 & 11.1 & 1 & 4.7 & \\
\hline Head shake test & 7 & 21.2 & 8 & 22.2 & 6 & 28.5 & 0.807 \\
\hline Head impulse test & 0 & 0 & 3 & 8.3 & 5 & 23.8 & 0.011 \\
\hline Gaze test & 0 & 0 & 0 & 0 & 0 & 0 & \\
\hline Oculomotor tests & 0 & 0 & 2 & 5.5 & 1 & 4.7 & 0.402 \\
\hline Saccade test & 0 & 0 & 0 & 0 & 0 & 0 & \\
\hline Smooth pursuit test & 0 & 0 & 2 & 5.5 & 1 & 4.7 & \\
\hline Optokinetic test & 0 & 0 & 0 & 0 & 0 & 0 & \\
\hline Spontaneous nystagmus test & 2 & 6.0 & 3 & 8.3 & 4 & 19.0 & 0.274 \\
\hline
\end{tabular}

${ }^{*}$ Chi-square test

dizziness. Therefore, dizzy individuals who experience motion sickness may feel more disability.

The cervical region is responsible for many vital functions as well as has a key role in maintaining balance. The cervical region has an important role in the function of both the vessels feeding the vestibular end organs and balance-related reflexes such as vestibulo-colic reflex, tonic neck reflex and oculomotor reflexes. Therefore, cervical spine disorder is thought to cause dizziness. Pathology of cervical spine in cervicogenic dizziness may cause permanent insufficiency and psychological problems characterized by neck and headache [10]. Malmström et al. [11] reported that dizzy patients frequently have head, neck and shoulder pain, and these patients have worse emotional and functional disabilities. In our study, 19 $(21.1 \%)$ of dizzy patients had cervical disc herniation. Besides, these patients with neck hernia had a more severe DDL, similar to Malmström's study. Cervical neck hernia may cause limited 
neck movement and chronic pain in patients and this may increase dizziness disability perception in dizzy individuals.

It is stated in the literature that there is no relationship between DDL and gender and age [7,12]. Similarly, in our study, there was no relationship between gender and DDL. However, in our study, older patients had more severe functional disability. With aging, the muscles in the lower limbs are weakened, and there are changes in vestibular, probrioceptive and visual inputs. This may affect the functional balance ability in the elderly and increase functional disability.

In our study, it was found that there was a positive relationship between duration of dizziness and DDL. Prolonged dizziness can cause fear and negative thoughts in patients and especially increase emotional disability. Besides, these patients may be more functionally affected due to the longterm change in daily life activities. It has also been reported that patients with prolonged dizziness, who support our findings, benefit less from the vestibular rehabilitation program [13].

The symptoms of some vestibular diseases may differ [14]. These dizziness types can be severe true vertigo, lightheadedness, or both (true vertigo and lightheadedness). In our study, we classified the patients according to dizziness types. Twenty-nine of the patients $(32.2 \%)$ described true vertigo, 41 patients (45.6\%) described lightheadedness, and 20 $(22.2 \%)$ patients described both vertigo and lightheadedness. There was no relationship between DDL and dizziness types of patients. Besides, there was no difference between DDL and smoking, alcohol use, working status, and falls.

The relationship between vestibular tests used to evaluate the vestibular system and DDL has been investigated in some studies [7,15-17]. Mandala et al. [15] stated that individuals with abnormal HIT have more severe DDL. Besides, they reported that there was no relationship between the caloric test and DDL. Herdman et al. [16] investigated the relationship between DDL and caloric test, VHIT and postural control tests in individuals with dizziness. As a result, they stated that there was no relationship between vestibular tests and DDL. Whitney et al. [7] stated that there was a relationship between DDL and sit-and-go test in individuals with vestibular hypofunction, while there was no relationship between DDL and time up to go test. Another study [17] reported that individuals with spontaneous nystagmus and individuals with decreased postural stability had more severe DDL. In our study, there was no relationship between DDL and Fukuda test, tandem walking test, dynamic positional tests, head shake test, oculomotor tests and spontaneous nystagmus test. However, individuals with abnormal HIT and abnormal tandem stance test had more severe DDL. Only overt saccades can be detected with HIT, and such saccades usually occur in acute lateral SSC or superior vestibular nerve lesions [18]. However, due to vestibular compensation, overt saccades disappear in the following period [19]. Therefore, patients with abnormal HIT often have severe vertiginous symptoms. These severe complaints, which started acutely, can cause severe disability in individuals.

The balance is maintained by correct processing of vestibular, probrioceptive and visual inputs in the cerebellum [20]. Visual inputs are prevented and proprioceptive inputs are reduced in the tandem posture test, which is used in the evaluation of functional static balance. In this way, the vestibular system is evaluated under difficult static conditions. Dizzy individuals with abnormal tandem posture tests may have more functional difficulties and this may increase DDL.

\section{CONCLUSION}

DDL is multidimensional and does not only depend on vestibular damage or vestibular tests. Motion sickness, cervical disc herniation, duration of dizziness, abnormal HIT and abnormal tandem stance test increase the disability level of dizzy patients. These factors should be considered in dizziness therapies applied to reduce vestibular symptoms and improve quality of life.

Author contributions: All authors have sufficiently contributed to the study, and agreed with the results and conclusions.

Funding: No funding source is reported for this study.

Declaration of interest: No conflict of interest is declared by authors.

\section{REFERENCES}

1. Weidt S, Bruehl AB, Straumann D, Hegemann SC, Krautstrunk G, Rufer M. Health-related quality of life and emotional distress in patients with dizziness: a crosssectional approach to disentangle their relationship. BMC Health Serv Res 2014;14:317-26. https://doi.org/10.1186/ 1472-6963-14-317 PMid:25052136 PMCid:PMC4119060

2. Bayat A, Saki N. Effects of Vestibular Rehabilitation Interventions in the Elderly with Chronic Unilateral Vestibular Hypofunction. Iran J Otorhinolaryngol 2017;29(93):183-8.

3. Jacobson GP, Newman CW. The development of the dizziness handicap inventory. Arch Otolaryngol Head Neck Surg 1990;116(4):424-7. https://doi.org/10.1001/archotol. 1990.01870040046011 PMid:2317323

4. Mutlu B, Serbetcioglu B. Discussion of the dizziness handicap inventory. J Vestib Res 2013;23(6):271-7. https://doi.org/10.3233/VES-130488 PMid:24447966

5. Yip CW, Strupp M. The Dizziness Handicap Inventory does not correlate with vestibular function tests: a prospective study. J Neurol 2018;265(5):1210-8. https://doi.org/10.1007 /s00415-018-8834-7 PMid:29557501

6. Pérez N, Martin E, Garcia-Tapia R. Dizziness: relating the severity of vertigo to the degree of handicap by measuring vestibular impairment. Otolaryngol Head Neck Surg 2003;128(3):372-81. https://doi.org/10.1067/mhn.2003.102 PMid: 12646840

7. Whitney SL, Wrisley DM, Brown KE, Furman JM. IS perception of handicap related to functional performance in persons with vestibular dysfunction? Otol Neurotol 2004;25(2):139-43. https://doi.org/10.1097/00129492200403000-00010 PMid:15021773

8. Reason JT, Brand JJ. Motion Sickness. London: Academic Press; 1975.

9. Henriques IF, Douglas de Oliveira DW, Oliveira-Ferreira F, Andrade PM. Motion sickness prevalence in school children. Eur J Pediatr 2014;173(11):1473-82. https://doi.org/10.1007/s00431-014-2351-1 PMid:24893949

10. Wrisley DM, Sparto PJ, Whitney SL, Furman JM. Cervicogenic dizziness: a review of diagnosis and treatment. J Orthop Sports Phys Ther 2000;30(12):755-66. https://doi.org/10.2519/jospt.2000.30.12.755

PMid:11153554 
11. Malmström EM, Magnusson M, Holmberg J, Karlberg M, Fransson PA. Dizziness and localized pain are often concurrent in patients with balance or psychological disorders. Scand J Pain 2019;28. https://doi.org/10.1515/ sjpain-2019-0121 PMid:31881001

12. Cheng YY, Kuo CH, Hsieh WL, Lee SD, Lee WJ, Chen LK, et al. Anxiety, depression and quality of life $(\mathrm{Q} O \mathrm{~L})$ in patients with chronic dizziness. Arch Gerontol Geriatr. Arch Gerontol Geriatr 2012;54(1):131-5. https://doi.org/10.1016/j.archger. 2011.04.007 PMid:21561671

13. Bamiou DE, Davies RA, McKee M, Luxon LM. Symptoms, disability and handicap in unilateral peripheral vestibular disorders. Effects of early presentation and initiation of balance exercises. Scand Audiol 2000;29(4):238-44. https:// doi.org/10.1080/010503900750022862 PMid:11195943

14. Branch WT, Barton JJ. Approach to the patient with dizziness. UpToDate ${ }^{\circledR} ; 2014$.

15. Mandalà M, Nuti D. Long-term follow-up of vestibular neuritis. Ann N Y Acad Sci 2009;1164:427-9. https://doi.org/ 10.1111/j.1749-6632.2008.03721.x PMid:19645942
16. Herdman D, Norton S, Pavlou M, Murdin L, Moss-Morris R. Vestibular deficits and psychological factors correlating to dizziness handicap and symptom severity. J Psychosom Res 2020;132:109969. https://doi:10.1016/j.jpsychores. 2020.109969 PMid:32097770

17. Jacobson GP, Newman CW, Hunter L, Balzer GK. Balzer, Balance function test correlates of the Dizziness Handicap Inventory. J Am Acad Audiol 1991;2(4):253-60.

18. Halmagyi GM, Curthoys IS. A clinical sign of canal paresis. Arch Neurol 1988;45(7):737-9. https://doi.org/10.1001/ archneur.1988.00520310043015 PMid:3390028

19. Sjögren J, Fransson PA, Karlberg M, Magnusson M, Tjernström F. Functional Head Impulse Testing Might Be Useful for Assessing Vestibular Compensation After Unilateral Vestibular Loss. Front Neurol 2018 Nov 19;9:979. https://doi.org/10.3389/fneur.2018.00979 PMid:30510538 PMCid:PMC6252383

20. Fetter M, Dichgans J. How do the vestibulo-spinal reflexes work? In: Baloh RW, Halmagyi GM, eds. Disorders of the Vestibular System, New York: Oxford University Press 1996:105-12. 